\title{
Alterações clínicas e patológicas durante a infecção experimental com Eimeria acervulina em frangos de corte suplementados com betaína*
}

\section{Clinical and pathological changes during the experimental infection with Eimeria acervulina in broiler chickens suplemented with betaine*}

\author{
Marcel Teixeira, ${ }^{* *}$ Tania Marcia Soares Niang, ${ }^{* *}$ Augusto Vidal da Costa Gomes, ${ }^{* * *}$ Walter Leira Teixeira Filho, ${ }^{* * * *}$ \\ Carlos Wilson Gomes Lopes*****
}

\begin{abstract}
Resumo
Com o objetivo de se avaliar o efeito da betaína na patogenicidade de Eimeria acervulina, 420 pintos de corte Cobb foram inoculados experimentalmente com $2 \times 10^{5}$ oocistos esporulados e alocados em baterias num esquema de blocos ao acaso com cinco tratamentos e seis repetições, incluindo-se um controle positivo, um grupo tratado com o anticoccidiano salinomicina e promotor de crescimento, e mais três níveis de betaína como aditivo na ração a 0,05, 0,10 e $0,15 \%$. No $14^{\circ}$ dia de vida as aves foram individualmente infectadas com $2 \times 10^{5}$ oocistos esporulados. A betaína não foi capaz de interferir positivamente na resposta clínica e patologia das aves durante a infecção por $E$. acervulina, no entanto foi capaz de aumentar a produção de oocistos. É provável que a betaína possa ser utilizada como aditivo na ração das aves em substituição aos medicamentos convencionais salinomicina e penicilina G potássica, cujos efeitos são semelhantes na recuperação do hospedeiro frente à coccidiose.
\end{abstract}

Palavras-chave: pintos de corte, coccidiose, infecção experimental, Eimeria acervulina, betaína.

\begin{abstract}
Purposing to investigate the betaine effect on biology and morphology of developmental stages of Eimeria acervulina, $420 \mathrm{Cobb}$ broiler chicks were experimentally inoculated with $2 \times 10^{5}$ sporulated oocysts and housed in battery cages in a block design with five treatments and six replicates each, including a positive control, a group treated with the anticoccidial salinomycin plus antibiotic growth promoter plus three levels of betaine as additive in the feed $0.05,0.10$ and $0.15 \%$. Betaine was not able to affect the clinical response and pathology during the infection, but improved oocyst output, possibly due to the osmotic mechanisms. In fact betaine could replace salinomycin plus growth promoter as additive in the feed which effects is closer in the recovery of the host affected by coccidiosis.
\end{abstract}

Keywords: broiler chicks, coccidiosis, experimental infection, Eimeria acervulina, betaine.

\section{Introdução}

Os efeitos significativos da aplicação da betaína na nutrição avícola têm sido apresentados desde meados dos anos 40 (Almquist e Grau, 1943). Conforme consta, os benefícios têm sido atribuídos a dois mecanismos metabólicos principais: ação como osmólito reduzindo a demanda energética para manutenção da água celular e o equilíbrio iônico; ação doadora de grupamentos metila para diversas reações de transme- tilação que trazem benefícios para o desempenho produtivo com menor custo de produção (Kettunen, 2001a).

O efeito osmorregulador exercido pela betaína na mucosa intestinal baseia-se na manutenção desta delicada estrutura em momentos de estresse como o desafio pela coccidiose, durante o qual a diarréia e desidratação levam a interrupção da digestão e absorção de nutrientes por afetarem a atividade metabólica. Embora isso seja particularmente verdadeiro os resultados práticos observados até o momento têm sido um

* Sob os auspícios do CNPq e CAPES.

** Departamento de Ciências Agrárias e Ambientais Universidade Estadual de Santa Cruz. Campus Soane Nazaré de Andrade. Rodovia Ilhéus/ Itabuna Km 16, Ilhéus, Bahia. Bolsista Fapesb E-mail: teixeira@ufrrj.br

*** Curso de Pós-Graduação em Zootecnia. BR-465 - Km-7 - Universidade Federal Rural do Rio de Janeiro (UFRRJ). $23890-000$ Seropédica, RJ. E-mail: tania222soares@yahoo.com.br

**** Departamento de Produção Animal. Instituto de Zootecnia da UFRRJ. 23890-000 Seropédica, RJ. E-mail: vidal@ufrrj.br

**** Departamento de Parasitologia Animal. Instituto de Veterinária da UFRRJ 23890-000 Seropédica, RJ. Bolsista CNPq. E-mail: leira@ufrrj.br, lopescwg@ufrrj.br 
tanto controversos. Sendo assim pode-se dizer que o conhecimento do uso da betaína é ainda incipiente, faltando maiores esclarecimentos principalmente nas questões da relação parasito-hospedeiro que envolve desde 0 desenvolvimento do parasito até o modo pelo qual ele afeta o hospedeiro.

O presente trabalho aborda o efeito do uso da betaína na patogenicidade da infecção por Eimeria acervulina, com base nos dados clínicos e patológicos associados ao desempenho das aves.

\section{Material e métodos}

Foram utilizadas no estudo 420 pintos de corte Cobb distribuídos em baterias de metal num delineamento por blocos ao acaso constituído de cinco tratamentos e seis repetições de 14 aves cada. A dieta basal (Rostagno et al., 2000) era fornecida em duas fases sendo (1-21 e 22-43 dias de idade) sendo água e comida fornecidas ad libitum. A suplementação de betaína (Betafin ${ }^{\circledR} 96 \%$ de pureza) foi feita em substituição ao ingrediente inerte na ração. As dietas foram separadas em: T1 (dieta basal + salinomicina $20.000 \mathrm{mg} / \mathrm{kg}$ + penicilina G potássica $2.00 \mathrm{mg} / \mathrm{kg}$ ); T2 (controle positivo - dieta basal); T3 (dieta basal + betaína 0,05\%); T4 (dieta basal + betaína $0,10 \%$ ) e T5 (dieta basal + betaína 0,15\%).

O material infectante era composto de E. acervulina cepa Ea3LPL8a (Embrapa) preparado conforme Ercket et al. (1999). A infecção das aves ocorreu no 14ํำ dia de vida ou 0 DAl (dias após a infecção) individualmente com a dose de $2 \times 10^{5}$ oocistos esporulados por via oral. Após a infecção, diariamente no período da manhã, as aves foram inspecionadas para observação de sinais clínicos como diarréia, anorexia e mortalidade. $O$ ganho de peso e o consumo de ração foram determinados nos períodos de 0-7 e 7-14 DAÍ. A dosagem de proteínas plasmáticas totais foi realizada conforme Lowry et al. (1951).

A avaliação patológica compreendeu a observação do escore de lesão (Johnson e Reid, 1970), histopatologia de seções do duodeno e morfologia das vilosidades. Para tanto realizaram-se necropsias no $0,4 \div$, 7ㅇ e 14을 $\mathrm{DAl}$, utilizando-se uma ave por repetição. Fragmentos de aproximadamente $2 \mathrm{~cm}$ eram retirados do duodeno de cada ave e fixados com solução de formol neutro a $10 \%$. Os tecidos foram processados por técnica de inclusão em parafina ou Histosec ${ }^{\circledR}$ (Merck), cortados com aproximadamente $5 \mu \mathrm{m}$ e corados pela hematoxilina e eosina (HE) e Periodic Acid Schiif (PAS) conforme Behmer et al. (1976). A morfologia das vilosidades intestinais foi realizada mensurando-se altura de vilosidade e profundidade de cripta, utilizando-se microscópio binocular Carl Zeiss (RFA) em aumento de 40 vezes, acoplado de ocular micrométrica K15x-PZO (Polônia). Foram efetuadas para cada tratamento 30 medidas dos três parâmetros.

Todo o método de análise laboratorial foi feito conforme Duszynski e Wilber (1997), exceto pela contagem de oocistos por grama de fezes realizada de acordo com Menezes e Lopes (1995). A produção total de oocistos foi dada pelo somatório das contagens de oocistos realizadas para cada tratamento.

As análises estatísticas foram realizadas conforme Sampaio (2002) com auxílio do programa SISVAR versão 4.6 (Ferreira, 2000).

\section{Resultados e discussão}

\section{Avaliação clínica}

No 3ํㅡㄹ observou-se o conteúdo esbranquiçado das fezes aumentado em aproximadamente $50 \%$ do plantel e variando em intensidade de gaiola para gaiola nos grupos experimentais, quase sempre associados com apatia das aves. No dia seguinte (4을 DAl) observou-se amolecimento do conteúdo fecal que progrediu para diarréia no 5 DAl, ainda assim, variando de gaiola para gaiola e dentro do mesmo grupo experimental. No 6을 a maioria das aves teve diarréia, aumento do conteúdo fecal de coloração esbranquiçada além do aspecto mucóide oriundo de uma intensa secreção. Tal observação ocorreu durante um período de aproximadamente 36 horas, sendo que nas aves do grupo controle (T2) estes sinais foram mais evidentes, acometendo $50 \%$ destas. Entre os grupos que receberam algum tipo de tratamento o estado clínico geral foi bom e o apetite normal, bem como a ingestão de água. No 7으 DAl todo o plantel apresentou sinais de recuperação evidentes. Nos dias posteriores ainda duas aves vieram a óbito, sendo uma delas no 16을 DAl no grupo T1 e outra no 17ํㅡㄹ DAl no grupo T3, por causa não determinada. Posteriormente todo o plantel permaneceu dentro da normalidade até o final do experimento. Os sinais clínicos foram acompanhados da observação de oocistos nas fezes. A taxa de mortalidade total no plantel foi de $1 \%$.

\section{Consumo de ração e ganho de peso}

Os valores do consumo de ração e de ganho de peso estão relacionados na Tabela 1. De acordo com os resultados obtidos no teste SNK, observa-se que nos períodos entre o 1응 e 7으 bem como de 7으 a 14음 DAI, não foi observada nenhuma diferença significativa $(p>0,05)$ no ganho de peso dos animais dentre os diversos tratamentos.

Tabela 1: Efeito dos tratamentos no consumo de ração e no ganho de peso das aves infectadas com $2 \times 10^{5}$ oocistos esporulados de Eimeria acervulina

\begin{tabular}{|c|c|c|c|c|c|}
\hline \multirow{3}{*}{ DAI } & & \multicolumn{4}{|c|}{ Avaliação (Kg) } \\
\hline & & \multicolumn{2}{|c|}{ Consumo de ração } & \multicolumn{2}{|c|}{ Ganho de Peso } \\
\hline & & $1^{\circ}-7^{0}$ & $7^{0}-14^{\circ}$ & $1^{\circ}-7^{\circ}$ & $7^{\circ}-14^{\circ}$ \\
\hline \multirow{5}{*}{ 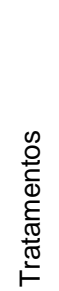 } & $\mathrm{T} 1$ & $0,744^{b}$ & $0,930^{b}$ & $0,403^{\mathrm{a}}$ & $0,665^{\mathrm{a}}$ \\
\hline & $\mathrm{T} 2$ & $0,742^{b}$ & $0,877^{\mathrm{ab}}$ & $0,393^{\mathrm{a}}$ & $0,587^{\mathrm{a}}$ \\
\hline & $\mathrm{T} 3$ & $0,742^{b}$ & $0,890^{\mathrm{ab}}$ & $0,375^{\mathrm{a}}$ & $0,634^{\mathrm{a}}$ \\
\hline & $\mathrm{T} 4$ & $0,712^{\mathrm{a}}$ & $0,853^{a}$ & $0,383^{a}$ & $0,656^{\mathrm{a}}$ \\
\hline & $\mathrm{T} 5$ & $0,722^{\mathrm{ab}}$ & $0,893^{\mathrm{ab}}$ & $0,384^{a}$ & $0,636^{\mathrm{a}}$ \\
\hline
\end{tabular}

abValores de média na mesma coluna sem sobrescrito comum diferem significativamente $(p<0,05)$ pelo teste $t$ de Student Newman Keuls (SNK). T1 (dieta basal + salinomicina $20.000 \mathrm{mg} / \mathrm{kg}$ + penicilina G potássica $2.00 \mathrm{mg} / \mathrm{kg}$ ); T2 (controle positivo - dieta basal); T3 (dieta basal + betaína 0,05\%); T4 (dieta basal + betaína 0,10\%); T5 (dieta basal + betaína $0,15 \%)$. 
Quanto ao consumo de ração, este foi afetado significativamente $(p<0,05)$, sendo que o grupo que recebeu betaína a $0,1 \%$ na ração (T4) teve consumo menor em relação aos grupos $\mathrm{T} 1$, que recebeu ração com salinomicina e promotor de produção, T2 (controle positivo) e T3, aves suplementadas com betaína $0,05 \%$. No período seguinte, o grupo T4 teve um consumo de ração menor que os demais, porém significativamente inferior ao grupo suplementado com medicação anticoccidiana.

Matthews et al. (1997) observaram aumento tanto no consumo de ração como no ganho de peso de frangos de corte suplementados com esse mesmo nível de betaína na ração, porém as aves foram infectadas com $5 \times 10^{5}$ oocistos esporulados de E. acervulina. Hipoteticamente esta diferença poderia ser causada pela quantidade de oocistos inoculados e por isso uma maior severidade da infecção. Porém, num estudo posterior Matthews e Southern (2000) observaram efeitos contraditórios mesmo entre dois experimentos elaborados com o mesmo protocolo. Embora a betaína tivesse afetado positivamente $\mathrm{o}$ ganho de peso das aves durante a infecção crônica com 2,5 x $10^{5}$ oocistos esporulados de $E$. acervulina, observaram o efeito oposto nas aves não infectadas ou naquelas infectadas com $5 \times 10^{6}$ oocistos esporulados. Esteve-Garcia e Mack (2000) também não conseguiram observar uma resposta significativa quanto ao ganho de peso com o uso da betaína em frangos de corte não infectados. Almquist e Grau (1943) já haviam relatado que tal efeito positivo no ganho de peso dependia de certas condições tais como a deficiência de colina.

Klasing et al. (2002), ao infectar aves com 4,6 $\times 10^{4}$ oocistos de $E$. acervulina, observaram incapacidade da betaína nos níveis 0,$0 ; 0,5$ e $0,10 \%$ em afetar tanto o consumo de ração como o ganho de peso dos animais. Diferentemente, Waldenstedt et al. (1999) observaram efeitos positivos no peso vivo das aves alimentadas com betaína $0,1 \%$ utilizando uma cultura mista com várias espécies do gênero Eimeria e mais recentemente, embora Fetterer et al. (2003) tenham observado um ganho de peso significativamente melhor nas aves alimentadas com betaína $0,15 \%$ na ração e infectadas com E. máxima, o mesmo não foi observado com a infecção por $E$. acervulina ou E. tenella. Estes fatos demonstram que as variações na metodologia aplicada podem explicar em parte a ocorrência de discrepâncias entre os resultados, mas não é provavelmente o único motivo, podendo haver outros até então não determinadas.

\section{Proteínas plasmáticas totais}

Pouca diferença foi observada entre os níveis de proteínas nos dias avaliados (Tabela 2). No 4- DAI, devido à perda de muitas parcelas, o tratamento 1 não foi incluído na comparação estatística de médias. Quando comparados os demais grupos embora T3 tivesse menor nível de proteínas plasmáticas e T4 o maior, estes valores não foram diferentes significativamente $(p<0,05)$. No 70 DAl o grupo tratado com betaína $0,15 \%$ (T5) teve os menores níveis de proteínas sendo, porém, diferente estatisticamente somente em relação ao T1 com o maior nível de proteínas plasmáticas.

No 14 DAl, embora o grupo T2 tenha apresentado o menor nível de proteínas e T5 o maior também não houve significância estatística. Assim como observado durante a ava-
Tabela 2: Níveis de proteínas plasmáticas de frangos de corte infectados com $2 \times 10^{5}$ oocistos de Eimeria acervulina

\begin{tabular}{ccc}
\hline $\begin{array}{c}\text { Dias após } \\
\text { infecção }\end{array}$ & Tratamentos & Média $(\mu \mathrm{g} / \mu \mathrm{l})$ \\
\hline \multirow{3}{*}{4} & T1 & - \\
& T3 & $39,42^{\mathrm{a}}$ \\
& T5 & $40,45^{\mathrm{a}}$ \\
& T2 & $42,10^{\mathrm{a}}$ \\
& T4 & $44,97^{\mathrm{a}}$ \\
\hline \multirow{3}{*}{7} & T5 & $31,20^{\mathrm{a}}$ \\
& T3 & $36,07^{\mathrm{a}, \mathrm{b}}$ \\
& T4 & $37,20^{\mathrm{a}, \mathrm{b}, \mathrm{c}}$ \\
& T2 & $39,20^{\mathrm{a}, \mathrm{b}, \mathrm{c}}$ \\
& T1 & $45,87^{\mathrm{b}, \mathrm{c}}$ \\
\hline \multirow{2}{*}{14} & T2 & $32,77^{\mathrm{a}}$ \\
& T3 & $34,45^{\mathrm{a}}$ \\
& T1 & $38,37^{\mathrm{a}}$ \\
& T4 & $38,82^{\mathrm{a}}$ \\
& T5 & $43,33^{\mathrm{a}}$ \\
\hline
\end{tabular}

${ }^{a b c}$ Valores de média na mesma coluna sem sobrescrito comum diferem significativamente $(p<0,05)$ pelo teste de Tukey. T1 (dieta basal + salinomicina $20.000 \mathrm{mg} / \mathrm{kg}$ + penicilina G potássica $2.00 \mathrm{mg} / \mathrm{kg}$ ); T2 (controle positivo - dieta basal); T3 (dieta basal + betaína 0,05\%); T4 (dieta basal + betaína 0,10\%); T5 (dieta basal + betaína 0,15\%).

liação do ganho de peso o fato de um grupo tratado com betaína ter níveis menores de proteínas plasmáticas foi inesperado, não sendo possível uma explicação. Mathews e Southern (2000) também observaram níveis menores de proteínas plasmáticas nas aves suplementadas com betaína, porém o fato ocorreu com aves não infectadas por Eimeria enquanto nas aves infectadas com 2,5 × $10^{5}$ oocistos de $E$. acervulina, a suplementação com betaína a 0,1\% melhorou os níveis de proteínas plasmáticas em dois experimentos distintos. Anteriormente a estes autores, nenhuma referência ao efeito da betaína no nível de proteínas plasmáticas durante a coccidiose foi relatada.

\section{Patologia}

As lesões encontradas a partir do 4- DAI localizavam-se no duodeno, algumas vezes se estendendo até o jejuno e íleo. As lesões iniciais eram pequenas placas esbranquiçadas, evoluindo para lesões de aspecto branco-amarelado ou totalmente amarelado.

A mucosa intestinal dos animais apresentou espessamento e produção de muco intenso já no $4^{\circ}$ DAl e áreas hiperêmicas e petéquias foram observadas no $7^{\circ}$ DAl. Nas aves do 14을 em diante não foram observadas lesões, apesar do intestino delgado permanecer ainda com espessamento e muco. Ao efetuar o escore observou-se que em determinados momentos as lesões eram menos severas em alguns grupos tratados com a betaína. No entanto, não se observou diferença significativa $(p>0,05)$ entre os grupos (Tabela 3$)$. Este fato, associado à falta de mais trabalhos que abordam tal questão, dificulta a comparação com o presente trabalho. Sendo assim, 
nestas condições experimentais, não se pode atribuir definitivamente à betaína uma ação efetiva na diminuição das lesões por coccidiose.

Tabela 3: Valores médios do escore de lesões em frangos de corte infectados com $2 \times 10^{5}$ oocistos de Eimeria acervulina

TRATAMENTOS

T1

\begin{tabular}{|c|c|c|c|c|c|c|}
\hline \multirow{3}{*}{$\begin{array}{l}\text { : } \\
\text { 유 } \\
\text { صू }\end{array}$} & $0 \mathrm{DAl}^{\mathrm{a}}$ & - & - & - & - & - \\
\hline & $4^{\circ} \mathrm{DAl}$ & $1,2^{b}$ & $1,5^{\mathrm{b}}$ & $0,7^{\mathrm{b}}$ & $1,2^{b}$ & $1,2^{b}$ \\
\hline & $7^{\circ} \mathrm{DAl}$ & $2,3^{b}$ & $2,2^{b}$ & $1,7^{b}$ & $1,5^{b}$ & $2,0^{b}$ \\
\hline
\end{tabular}

${ }^{a}$ Dias após infecção. ${ }^{b}$ Valores de média na mesma linha sem sobrescrito comum diferem significativamente $(p<0,05)$ pelo teste de Tukey. T1 (dieta basal + salinomicina $20.000 \mathrm{mg} / \mathrm{kg}$ + penicilina G potássica $2.00 \mathrm{mg} /$ $\mathrm{kg}$ ); T2 (controle positivo - dieta basal); T3 (dieta basal + betaína 0,05\%); T4 (dieta basal + betaína 0,10\%); T5 (dieta basal + betaína 0,15\%).

Virtanen et al. (1996) reportaram a redução no escore de lesão de aves alimentadas com betaína associada à salinomicina, porém Remus e Virtanen (1996) não observaram quaisquer efeitos positivos. Mathews et al. (1997) também observaram a diminuição no escore de lesão quando combinaram betaína $0,1 \%$ com coccidiostático inonóforo, monensina a 55-110ppm na ração, mas observaram aumento no escore de lesões de algumas aves quando utilizaram apenas a betaína como aditivo durante a infecção experimental.

Anteriormente à infecção (DAI) não foram observadas lesões ou formas endógenas dos parasitos. De modo geral, as formas endógenas observadas foram predominantemente trofozoítos pequenos e redondos localizados na periferia das vilosidades intestinais estando os esquizontes no início de sua formação. Com relação aos grupos experimentais, excetuando-se T2 um pouco mais afetado, não foi possível determinar maior severidade para um ou outro grupo tratado, pois embora em alguns cortes histológicos as lesões e os parasitos em desenvolvimento fossem mais numerosos, tal diferença ocorria também entre animais de um mesmo grupo. Nos cortes em que a estrutura geral das vilosidades estava danificada, eram comuns fusões e espessamento das vilosidades, bem como edema e infiltrado inflamatório. Aparentemente o número de células caliciformes estava aumentado nas áreas parasitadas. A partir do 7음 $\mathrm{DA}$ presença de trofozoítos e esquizontes deram lugar às formas endógenas em fase sexuada caracterizadas pela presença de macro e microgametócitos, zigotos e oocistos imaturos. Neste período a lesão mais comumente encontrada foi o achatamento da mucosa, com fusão e encurtamento das vilosidades (aspecto polipóide). A erosão do epitélio era constante nas áreas com intensa formação e liberação de oocistos. Em algumas regiões foi comum observar que a camada submucosa estava hipertrofiada, além de abrigar células inflamatórias constituídas principalmente de linfócitos.
No 14ํำ DAl a estrutura da mucosa intestinal das aves tinha ainda bastante espessamento e apesar da ausência de formas endógenas.

Pode-se inferir que as alterações histopatológicas, bem como a morfologia do parasito permaneceram semelhantes entre os tratamentos. Embora não existam trabalhos relacionando diretamente os efeitos da betaína com as alterações microscópicas, alguns pesquisadores (Kettunen et al., 2001a e 2001b; Fetterer et al., 2003) se preocuparam em avaliar seu efeito intracelular, o que pode ser de utilidade no entendimento dos resultados encontrados. Sabe-se que a betaína dietética é absorvida principalmente na porção proximal do intestino delgado, acumulando-se em maior concentração no duodeno onde poderá exercer modulação do movimento de água através das membranas celulares melhorando a osmorregulação. Neste caso aves infectadas por E. acervulina teoricamente teriam mais chances de obter benefícios com o controle osmótico e responder melhor à infecção. Augustine et al. (1997) afirmaram que a betaína sozinha não foi capaz de afetar in vitro a morfologia, a invasão e o desenvolvimento dos esporozoítos de E.acervulina e E. tenella em níveis até oito vezes o usual. Porém, quando fornecida na alimentação das aves e avaliada a ultra-estrutura das células intestinais foi observado o oposto, indicando que sua atuação esteja na dependência do ambiente intestinal. Ainda, tais efeitos foram superiores quando a betaína foi associada à salinomicina. Klasing et al. (2002) afirmaram que a betaína é capaz de aumentar a quantidade de linfócitos intra-epiteliais no duodeno e melhorar a capacidade funcional dos fagócitos, o que sugere um importante fato na defesa do organismo do hospedeiro contra o parasitismo.

Quanto à morfologia das vilosidades intestinais, observouse que o maior impacto da coccidiose sobre a mucosa duodenal ocorreu no 7으 DAl onde o aumento na espessura da lâmina própria foi mais intenso devido à proliferação das criptas. Conseqüentemente nesta data a relação vilo/cripta (v/ c) foi pior em todos os grupos, mas embora isso signifique menor capacidade de absorção de nutrientes para o hospedeiro não refletiu negativamente no ganho de peso das aves. Essa condição foi mais acentuada no grupo controle positivo (T2) e se repetiu até a última análise que permaneceu com valores de v/c menores. Embora isto seja verdadeiro, nota-se que antes ou após a infecção a diferença entre os grupos experimentais não foi significativa $(p>0,05)$ com exceção do grupo T3 em relação ao T4 no 7ํ DAI. Esses resultados diferem daqueles encontrados por Kettunen et al. (2001a) que observaram no 7으 DAl uma melhoria na relação vilo/cripta no jejuno de aves infectadas com E. maxima, e também por Klasing et al. (2002) que relataram efeito modulador da betaína $0,1 \%$ na patogenia da infecção por $E$. acervulina através da redução no achatamento das vilosidades.

Observa-se que embora a quantidade de parasitos administrada para produzir uma infecção moderada fosse suficiente para causar alterações na morfologia da mucosa duodenal no 7ํㅡㄹ DAl, nas condições experimentais desta pesquisa não pôde ser observada nenhuma diferença entre os tratamentos aplicados. O raciocínio aplicado anteriormente na interpretação da histopatologia deve ser aplicado aqui, pois ainda que o efeito da betaína na mucosa duodenal tenha sido reduzido, é semelhante ao efeito da medicação anticoccidiana na promoção de uma resposta à infecção pelo hospedeiro. 


\section{Produção de oocistos}

Através desta análise observou-se que a eliminação dos oocistos de E. acervulina iniciou no dia no $4^{\circ}$ DAl chegando próximo de zero no $22^{\circ}$ DAl. Durante este período, em todos os tratamentos ocorreram dois picos de produção, sendo o primeiro no 5ㅇ DAl e um segundo aos 10 DAI (Figura 1).

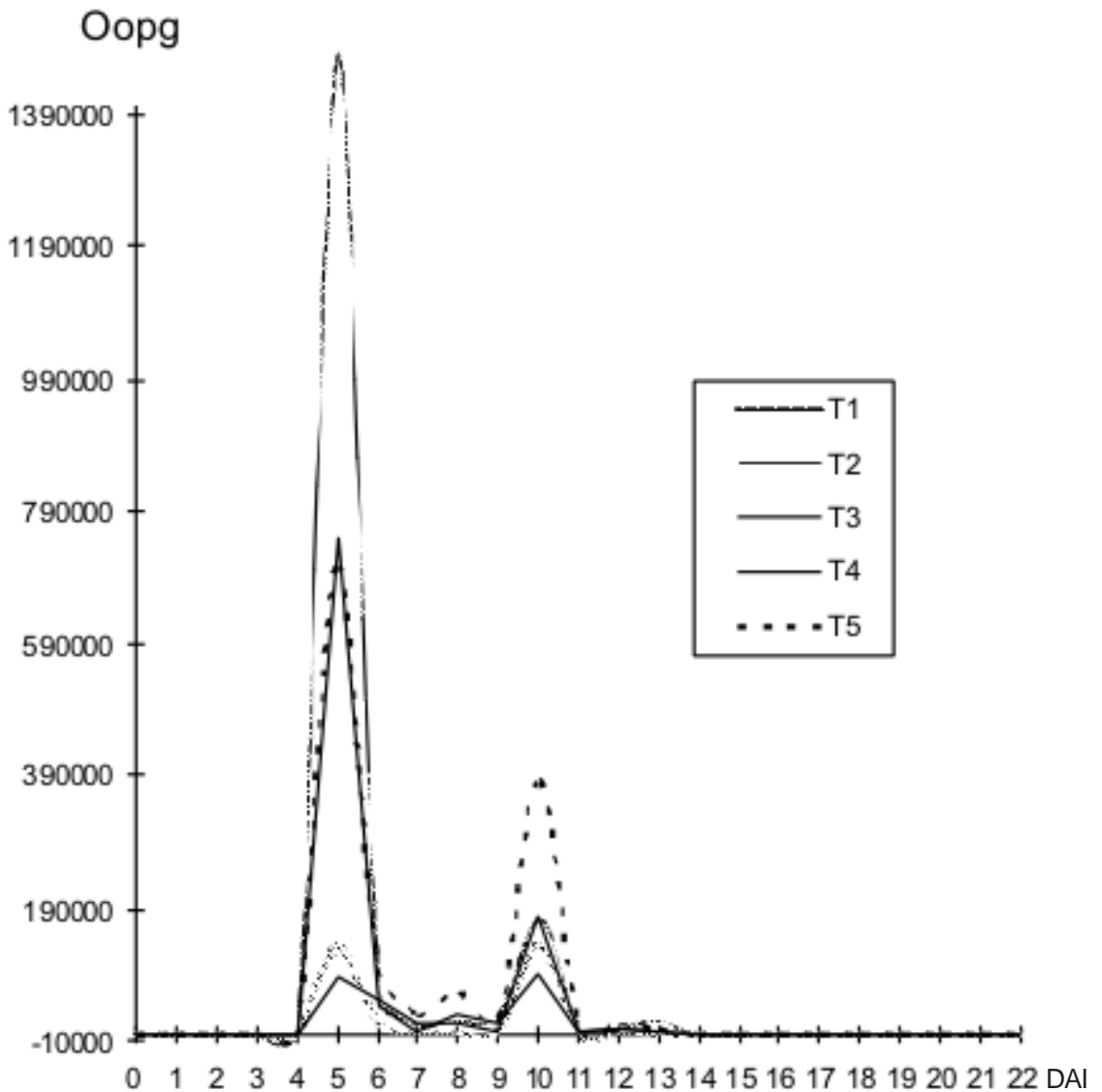

Fıgura 1: Lınämıca da produçao de oocıstos em trangos de corte intectados com $2 \times 10^{5}$ oocistos esporulados de Eimeria acervulina. T1 (dieta basal + salinomicina $20.000 \mathrm{mg} / \mathrm{kg}$ + penicilina G potássica $2.00 \mathrm{mg} / \mathrm{kg}$ ); T2 (controle positivo - dieta basal); T3 (dieta basal + betaína 0,05\%); T4 (dieta basal + betaína 0,10\%); T5 (dieta basal + betaína 0,15\%).

A observação da dinâmica da produção demonstra com clareza a superioridade do grupo T2 (controle) na eliminação de oocistos. Também com altos níveis de eliminação de oocistos se destacou o grupo T5, cuja produção ultrapassou a casa de milhão durante o período experimental. Um fato que também pode ser observado é que existe uma tendência de aumento da produção de oocistos na medida em que os níveis de betaína na dieta aumentaram. Uma hipótese para isso é que

\section{Referências}

ALMQUIST, H.J.; GRAU, C.R. Interrelationship of methionine, choline, betaine and arsenocholine in the chick. J. Nutr., v. 27, p. 263-269, 1943. AUGUSTINE, P.C.; MECNAUGHTON, J.L.; VIRTANEN, E. et al. Effect of betaine of the growth performance of chicks inoculated with mixed cultures of avian Eimeria species and on invasion and development of

\section{Conclusões} 1976. 256 p. a betaína, sendo um aditivo capaz de melhorar o equilíbrio osmótico das células do hospedeiro, poderia estar contribuindo secundariamente para o controle osmótico no parasito e conseqüentemente melhorando seu potencial reprodutivo. Contudo, as aves do grupo T1 eliminaram menos oocistos, pois em contraste com a betaína a medicação anticoccidiana utilizada atua comprometendo o equilíbrio osmótico do parasito e limitando a invasão e a reprodução das primeiras fases endógenas do parasito.

Entre os diversos parâmetros utilizados na avaliação da eficácia dos anticoccidianos a contagem de oocistos é considerada de pouca validade e muitas vezes controversa. O motivo pelo qual ela tem sido caracterizada dessa forma é a incoerência nos resultados com a contagem de oocistos.

Reid (1975) concluiu que este método de avaliação é de pouca validade, pois enquanto em alguns experimentos o número de oocistos foi reduzido com o uso da medicação, em outros aumentou substancialmente, chegando a mais que o dobro eliminado pelas aves não medicadas. Atribuiu a isso uma série de fatores tais como o tipo de medicamento, a dose utilizada, a espécie de Eimeria em questão e principalmente o efeito de superpopulação ou "crowding effect" (Fayer, 1980; Williams, 2001). No entanto, a betaína possui propriedades distintas de um medicamento anticoccidiano e neste contexto é que sua atuação na produção de oocistos foi avaliada. Contudo era esperado que, devido às suas propriedades osmorreguladoras, ela pudesse aumentar a produção de oocistos, que de acordo com os dados obtidos, realmente ocorreu. Estes dados diferem do que foi obtido por Waldenstedt et al. (1999), que não observaram efeitos positivos da betaína na eliminação de oocistos.

Com base nos resultados obtidos, pode-se concluir que nas condições experimentais a betaína não foi capaz de interferir positivamente na resposta clínica ou patologia das aves infectadas com E. acervulina. Porém existe a possibilidade de sua utilização como aditivo dietético em substituição aos medicamentos convencionais salinomicina e penicilina $G$ potássica, cujos efeitos foram semelhantes na recuperação do hospedeiro frente à coccidiose.

Eimeria tenella and Eimeria acervulina in vitro and in vivo. Poult. Sci., v. 76, p. 802-809, 1997.

BEHMER, O.A.; TOLOSA, E.M.C.; FERREIRA NETO, A.G. Manual de Técnicas para histologia normal e patológica. São Paulo: EDART,

CHAPMAN, H.D. Evaluation of the efficacy of anticoccidial drugs against Eimeria species in the fowl. Int. J. Parasitol., v. 28, p. 1441-1444, 1998. 
DUSZYNSKI, D.W.;WILBER, P.G. A guideline for the preparation of species descriptions in the Eimeriidae. J. Parasitol, v. 83, p. 333-336, 1997.

ECKERT, J.; BRAUN, R.; SHIRLEY, M. W. et al. Biotechnology: Guidelines on techniques in coccidiosis research, COST 89/820. Luxembourg: Office for Official Publications of the European Communities, 1995, $300 \mathrm{p}$.

ESTEVE-GARCIA, E.; MACK, S. The effect of DL-methionine and betaine on growth performance and carcass characteristics in broilers. An. F. Sc., v. 87, p. 85-93, 2000.

FAYER, R. Epidemiology of protozoan infections: the coccidia. Vet. Parasitol., v. 6, p. 75-103, 1980.

FERREIRA, D. F. Manual do Sistema SISVAR para Análises Estatísticas. UFLA: Lavras, MG, 63 p., 2000.

FETTERER, R.H.; AUGUSTINE, P.C.; ALLEN, P.C. et al. The effect of dietary betaína on intestinal and plasma levels of betaine in uninfected and coccidian-infected broiler chicks. Parasitol. Res., v. 90, p. 343348, 2003.

JOHNSON, J.; REID, W.M. Anticoccidial drugs: lesion scoring techniques in battery and floor-pen experiments with chickens. Exp. Parasitol., v. 28, p. 30-36, 1970.

KETTUNEN, H.; PEURANEM, S.; TIIHONEN, K. Betaine aids in the osmoregulation of duodenal epithelium of broiler chicks, and affects the movement of water across the small intestinal epithelium in vitro. Comp. Biochem. Physiol. Part A: Mol. Integr. Physiol., v. 129, p. 595603, 2001a.

KETTUNEN, H.; TIIHONEN, K.; PEURANEM, S. et al. Dietary betaine accumulates in the liver and intestinal tissue and stabilizes the intestinal epithelial structure in healthy and coccidia-infected broiler chicks. Comp. Biochem. Physiol. Part A: Mol. Integr. Physiol., v. 130, p. 759 - 769, 2001b.

KLASING, K.C.; ADLER, K.L.; REMUS, J.C. et al. Dietary betaine increases intraepithelial Lytmphocytes in the duodenum of coccidia-infected chicks and increases functional properties. J. Nutr., v. 132, p. 2274-2282, 2002.

LONG, P.L.; JOYNER, L.P.; MILLARD, B.J. et al. A guide to laboratory techniques used in the study and diagnosis of avian coccidiosis. Fol. Vet. Lat., v. 6, p. 201-216, 1976.
LOWRY, O.H.; ROSEBROUGH, N.J.; FARR, A.L. et al. Protein Measurement with the Folin Phenol Reagent. J. Biol. Chem., v. 193, p. 256-275, 1951.

MATTHEWS, J. O.; SOUTHERN, L. L. The effect of dietary betaine in Eimeria acervulina-infected chicks. Poult. Sci., v. 79, p. 60-65, 2000.

MATTHEWS; J.O.; WARD, T.L.; SOUTHERN, L.L. Interactive Effects of Betaine and Monensin in Uninfected and Eimeria acervulina-infected Chicks. Poul. Sci., v. 76, p. 1014-1019, 1997.

MENEZES, R.C.A.; LOPES, C.W.G. Epizootiologia da Eimeria arloingi em caprinos na microrregião Serrana Fluminense, Rio de Janeiro, Brasil. Rev. Univ. Rur., série Ci. Vida, v. 17, p. 5-12, 1995.

NIANG, T.M.S. Suplementação da Betaína e o Desenvolvimento e Características da Carcaça, Digestibilidade da Ração e o Desenvolvimento do Intestino Delgado de Frangos de Corte Infectados por Eimeria acervulina. 2005. 78 f. Dissertação (Mestrado em Zootecnia) - Universidade Federal Rural do Rio de Janeiro. Seropédica, 2005.

REID, W.M. Relative Value of Oocysts Counts in Evaluating Anticoccidial Activity. Av. Dis., v. 19, p. 803-811, 1975.

REMUS, J.; VIRTANEN, E. Use of liquid betaine in low methionine diets for broilers. Poul. Sci., v. 75, p. 35, 1996.

ROSTAGNO, H.S.; SILVA, D.J.; COSTA, P.M.A. et al. Composição de alimentos e exigências nutricionais de aves e suínos (Tabelas Brasileiras). Viçosa: Imprensa Universitária da UFV, 2000, 69 p.

SAMPAIO, I. B. M. Estatística aplicada à experimentação animal. 2. ed. Belo Horizonte: Fundação de estudo e pesquisa em Medicina Veterinária e Zootecnia, 2002. 265 p.

VIRTANEN, E.; REMUS, J.; ROSI, L. et al. The effect of betaine and salinomicyn during coccidiosis in broilers. Poult. Sci., v.75, p. 149, 1996.

WALDENSTEDT, L.; ELWINGER, K.; THEBO, P. et al. Effect of betaine supplement on broiler performance during an experimental coccidial infection. Poul. Sci., v. 78, p. 182-189, 1999. 